\title{
CELEBRITY PORTFOLIO EFFECTS ON CONSUMER BRAND EVALUATIONS
}

Max Yu, University of Queensland, Australia

Ravi Pappu, University of Queensland, Australia

\begin{abstract}
While much of the research on celebrity endorsement has focused on the retrospective evaluation of the brand in the context of a single celebrity endorsement, relatively less attention has been given to the effects of multiple celebrity endorsement. Previous research conceptualizes multiple celebrity endorsement simply as multiples of single celebrity endorsements, which has only considered the dyadic relationships between the celebrity endorser and the brand. The present research provides an improved conceptualization from a brand portfolio perspective and introduces the notion of celebrity portfolios. The present research explicitly considers the holistic evaluation of the celebrity portfolio instead of assuming independent evaluations. More importantly, the present research examines the interaction effects among the celebrities in the portfolio, on consumer brand evaluations which have not been considered in the current literature. Specifically, celebrity portfolio congruence is conceptualized as a three-dimensional concept by introducing two new dimensions of congruence: portfolio-brand congruence and celebrity-celebrity congruence. The results provided convergent evidence that the consumers evaluate celebrity portfolios holistically and support the interaction effects between the celebrities. The findings suggest that the impact of the number of celebrities used in a portfolio is more complex than previously assumed, in which, more is not necessarily better.
\end{abstract}

References Available Upon Request 